\title{
Analisis Teknis Terbaliknya KMP. Kayong Utara di Sungai Banyuasin, Sumatera Selatan
}

\author{
Mochamad Gizza Gaeta Nahumariri dan Hasanudin \\ Departemen Teknik Perkapalan, Fakultas Teknologi Kelautan, \\ Institut Teknologi Sepuluh Nopember (ITS) 60111 Indonesia \\ e-mail: hasanudin@na.its.ac.id
}

\begin{abstract}
Abstrak-Pada tanggal 20 Februari 2018, terjadi kecelakaan KMP. Kayong Utara yang terbalik di Sungai Banyuasin, Sumatera Selatan saat berlayar dari Pelabuhan Muntok, Bangka menuju Pelabuhan Tanjung Api-Api, Sumatera Selatan. Kapal memuat 8 truk sedang, 1 kendaraan kecil, dan 2 sepeda motor serta 9 penumpang dewasa dan 1 penumpang anak-anak. Perlu dilakukannya investigasi untuk mengetahui penyebab kecelakaan agar fenomena serupa tidak terulang kembali. Analisis dilakukan berdasarkan hasil temuan lapangan dari KNKT. Analisis dimulai dari pemodelan kapal dengan toleransi selisih displacement, LCG, dan volume tiap tangki kurang dari $0.2 \%$. Selanjutnya dilakukan analisis stabilitas pada saat kapal berangkat, setelah kapal berlayar 3 jam 40 menit, sesaat kapal setelah bebas dari kandas, saat kendaraan akan bergeser, dan kapal terbalik. Berdasarkan hasil temuan lapangan, kapal berangkat dengan keadaan tegak dengan sarat $1.7 \mathrm{~m}$ sehingga didapatkan displacement 356.4 ton, LCG 14.245 m, dan hasil pemeriksaan kriteria stabilitas adalah tidak memenuhi. Setelah berlayar selama 3 jam 40 menit, didapatkan konsumsi bahan bakar adalah 0.6025 ton serta konsumsi air tawar setidaknya 12.856 ton sebelum kapal kandas dengan kondisi miring $4^{\circ}$ ke kiri dan sedikit trim buritan. Hasil pemeriksaan kriteria stabilitas setelah berlayar adalah tidak memenuhi. Dilakukan upaya pembebasan dengan cara pemindahan 4 truk belakang dan air tawar sehingga kemiringan kapal berukurang $0.5^{\circ}$. Namun sesaat setelah bebas dari kandas, kapal terapung dan hasil pemeriksaan kriteria stabilitas adalah tidak memenuhi. Kapal terus miring ke kanan hingga kendaraan bergeser ke kanan pada sudut heel $5.71^{\circ}$ diakibatkan bekerjanya momen penegak dan tidak seimbangnya tangki air tawar. Kombinasi dari ketiga kondisi tersebut ternyata masih belum cukup untuk menyebabkan kapal terbalik dan rebah $90^{\circ}$. Terdapat 2 kemungkinan tambahan yang mendukung terbaliknya kapal yaitu isi tangki air kiri dikurangi menjadi $62 \%=32.164$ ton dan atau VCG lightship yang naik menjadi $1.8 \mathrm{~m}$ sehingga kapal dapat terbalik. Agar kejadian tidak terulang kembali maka dapat diantisipasi dengan penanganan muatan dan pemindahan isi tangki dengan hati-hati, melengkapi kapal dengan dokumendokumen yang terbaru dan akurat, serta meningkatkan pengetahuan ABK tentang stabilitas kapal.
\end{abstract}

Kata Kunci- investigasi kecelakaan kapal, stabilitas, terbalik, GZ negatif

\section{PENDAHULUAN}

K APAL sebagai salah satu moda transportasi penumpang maupun barang tidak lepas dari risiko terjadinya kecelakaan. Meningkatnya kejadian kecelakaan transportasi laut di Indonesia beberapa tahun terakhir semakin memprihatinkan. Kecelakaan pada transportasi laut yang terjadi di Indonesia diantaranya tenggelamnya kapal, tabrakan antar kapal serta kebakaran kapal. Selama Periode 2010-2016, telah terjadi 54 kecelakaan kapal di perairan Indonesia diantaranya tenggelam (24\%), kebakaran (35\%), kandas (6\%), tubrukan (31\%), serta penyebab lainnya (4\%) [1].

Pada tanggal 20 Februari 2018, dunia pelayaran Indonesia kembali berduka atas terjadinya kecelakaan KMP. Kayong Utara yang terjadi di Sungai Banyuasin, Sumatera Selatan. Kapal tersebut mengalami kecelakaan pada saat akan bertolak dari Pelabuhan Muntok, Bangka menuju Pelabuhan Tanjung Api-Api. Kapal tersebut memuat 8 truk sedang, 1 kendaraan kecil, dan 2 sepeda motor yang berada di geladak kendaraan serta terdapat 1 orang meninggal dunia [2].

Berdasarkan data dan fakta tersebut, maka perlu dilakukannya investigasi untuk mengetahui penyebab kecelakaan KMP. Kayong Utara. Tahap investigasi yang dilakukan adalah tahap analisis pada stabilitas kapal berdasarkan yang hasil temuan lapangan dengan bekerja sama dengan KNKT. Hasil dari penelitian ini diharapkan dapat mengetahui secara teknis penyebab dari kecelakaan pada KMP. Kayong Utara, sehingga dapat digunakan sebagai pembelajaran untuk mengatisipasi agar tidak terjadi hal serupa pada kapal lainnya.

\section{STUDI LITERATUR}

\section{A. Stabilitas Kapal}

Stabilitas kapal adalah kecenderungan sebuah kapal untuk kembali ke posisi semula setelah mendapat pengaruh dari luar. Pada saat kapal berlayar di suatu perairan, kapal akan selalu mendapat gaya-gaya baik gaya dari luar maupun dari dalam kapal itu sendiri. Gaya-gaya tesebut dapat mengenai badan kapal dan badan kapal akan merespon gaya-gaya tersebut [3].

Ketika sebuah kapal terapung kapal akan memberikan 6 jenis respon gerakan sebuah kapal yang dikenal dengan 6 derajat kebebasan. Hubungan antara stabilitas dengan 6 derajat kebebasan adalah sebagai berikut:

1) Gerakan translasi ke arah sumbu $Z$ atau heave memiliki keseimbangan stabil.

2) Gerakan translasi ke arah sumbu $X$ dan $Y$ atau surge dan sway memiliki keseimbangan netral atau indiferen.

3) Gerakan rotasi memutari sumbu $Z$ (vertikal) atau yaw memiliki keseimbangan netral atau indiferen.

4) Gerakan rotasi memutari sumbu $X$ dan $Y$ atau heel dan pitch: tidak tentu, mungkin keseimbangan stabil, labil atau netral.

Stabilitas yang dibahas hanyalah stabilitas berdasarkan gerakan rotasi pada sumbu $\mathrm{X}$ dan sumbu $\mathrm{Y}$ karena keadaan 
seimbangannya tidak tentu. Ilustrasi dari 6 derajat kebebasan dapat dilihat pada Gambar 1.
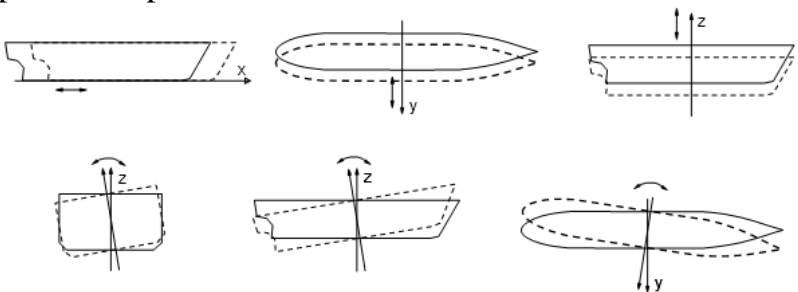

Gambar 1. 6 Derajat Kebebasan.

Sebuah kapal ketika dikenai gaya dari luar, kapal akan heel atau trim. Heel atau trim pada kapal akan mengubah bentuk badan kapal yang tercelup air. Jika bentuk badan kapal yang tercelup air berubah maka letak titik gaya tekan keatas (B) yang bekerja pada kapal juga akan berubah. Apabila titik G tetap dan titik B berubah, maka garis gaya yang bekerja pada kedua titik tersebut tidak lagi bekerja pada satu garis vertikal. Berdasarkan kondisi tersebut, maka akan terbentuklah momen kopel atau disebut momen penegak.

Keadaan seimbang pada kapal dapat terjadi jika jumlah gaya dan jumlah momen yang bekerja pada kapal terhadap suatu titik besarnya sama dengan nol. Terdapat 3 jenis keadaan seimbang pada sebuah kapal ketika mengapung yaitu stabil, indeferen, atau labil. Keseimbangan stabil adalah apabila setelah pengaruh luar yang bekerja pada suatu benda tersebut hilang, maka benda akan bergerak kembali ke kedudukan semula. Keseimbangan indiferen atau netral adalah apabila pengaruh luar yang bekerja pada suatu benda tersebut hilang, maka benda tersebut tidak kembali ke kedudukan awal, tetapi tetap pada kedudukannya yang baru. Keseimbangan labil adalah apabila pengaruh luar yang bekerja pada suatu benda tersebut hilang, benda tidak kembali ke kedudukan semula, tetapi bergerak terus menjauhi kedudukan semula.

Intact stability adalah perhitungan stabilitas kapal utuh (tidak bocor) yang dihitung pada beberapa kondisi tangki untuk tiaptiap derajat kemiringan kapal. Kapal dikatakan stabil tidak hanya mempunya lengan stabilitas positif, akan tetapi harus dibandingkan dengan kriteria stabilitas yang disyaratkan.

\section{B. Kecelakaan Kapal}

Kecelakaan kapal adalah suatu kejadian atau peristiwa yang mengakibatkan beberapa hal sebagai berikut:

1) Kematian/hilangnya nyawa seseorang, cedera/luka berat atas seseorang yang disebabkan karena atau berkaitan dengan kegiatan pelayaran atau operasional kapal; atau

2) Hilangnya seseorang dari kapal atau sarana apung lainnya yang disebabkan karena atau berkaitan dengan kegiatan pelayaran atau pengoperasian kapal; atau

3) Hilangnya, atau menghilangnya sebuah kapal atau lebih; atau

4) Kerusakan material pada sebuah kapal atau lebih; atau

5) Kandasnya atau tidak mampunya sebuah kapal atau lebih, atau keterlibatan sebuah kapal dalam kejadian tabrakan; atau

6) Kerusakan material/barang yang disebabkan karena atau berkaitan dengan, pengoperasian kapal; atau

7) Kerusakan lingkungan yang disebabkan oleh rusaknya sebuah kapal atau lebih, atau berkaitan dengan pengoperasian kapal [4].

\section{Karakteristik Kecelakaan Transportasi Laut}

Karakteristik kecelakaan menurut KNKT pada umumnya adalah:

1) Kecelakaan sebagai kejadian yang langka.

2) Kecelakaan sebagai suatu peristiwa yang tidak tahu kapan akan terjadi

3) Kecelakaan sebagai peristiwa-peristiwa multi faktor.

Karakteristik kecelakaan transportasi laut menurut KNKT dijelaskan pada Tabel 1 [4].

Tabel 1.

Karakteristik kecelakaan transportasi laut

\begin{tabular}{|c|c|c|}
\hline QW & Tipikal Kecelakaan & Objek \\
\hline WHAT & $\begin{array}{l}\text { 1) Tipe kecelakaan: } \\
\text { tenggelam, terbakar, tubrukan, } \\
\text { kandas. } \\
\text { 2) Tingkat kecelakaan }\end{array}$ & $\begin{array}{llr}\text { Kapal } & \text { Motor, Kapal } \\
\text { Layar Motor, Tug } \\
\text { Boat, Tanker dan } \\
\text { Tongkang. }\end{array}$ \\
\hline WHY & $\begin{array}{l}\text { 2) Faktor alam: } \\
\text { Cuaca buruk, badai, } \\
\text { gelombang tinggi yang } \\
\text { dipengaruhi oleh } \\
\text { musim/badai, arus yang besar, } \\
\text { kabut. } \\
\text { 3) Faktor Manusia } \\
\text { a. Kecerobohan. } \\
\text { b. Kurang mampunya } \\
\text { ABK dalam mengoperasijan } \\
\text { kapal. } \\
\text { c. Secara sadar memuat } \\
\text { kapal secara berlebihan. }\end{array}$ & $\begin{array}{l}\text { Pemilik kapal, Marine } \\
\text { Inspector, Awak } \\
\text { kapal, Galangan } \\
\text { kapal, dan Pemasok } \\
\text { Peralatan kapal. } \\
\text { Alur pelayaran, kolam } \\
\text { pelabuhan, dan } \\
\text { informasi BMKG. }\end{array}$ \\
\hline WHO & $\begin{array}{l}\text { Pihak yang terlibat kecelakaan } \\
\text { dan korban kecelakaan: } \\
\text { 1) Kapal yang terlibat } \\
\text { kecelakaan. } \\
\text { 2) Manusia. }\end{array}$ & $\begin{array}{l}\text { Nakhoda/ Juru mudi } \\
\text { kapal, ABK, dan } \\
\text { Penumpang. }\end{array}$ \\
\hline WHERE & $\begin{array}{l}\text { Lokasi tempat } \quad \text { kejadian } \\
\text { kecelakaan }\end{array}$ & $\begin{array}{l}\text { Alur pelayaran kapal, } \\
\text { kolam pelabuhan, } \\
\text { dermaga. }\end{array}$ \\
\hline WHEN & Waktu kejadian & $\begin{array}{l}\text { Kapal, Nakhoda, dan } \\
\text { penumpang }\end{array}$ \\
\hline HOW & $\begin{array}{l}\text { Kronologis kejadian kecelakaan: } \\
\text { 1) Pergerakan kapal. } \\
\text { 2) Kondisi kapal. }\end{array}$ & Kapal \\
\hline
\end{tabular}

\section{Investigasi Kecelakaan Transportasi}

Investigasi kecelakaan transportasi menurut Peraturan Pemerintah Nomor 62 Tahun 2013 tentang Investigasi Kecelakaan Transportasi adalah kegiatan penelitian terhadap penyebab kecelakaan transportasi dengan cara pengumpulan, pengolahan, analisis, dan penyajian data secara sistematis dan objektif agar tidak terjadi kecelakaan transportasi dengan penyebab yang sama [5]. 


\section{E. Karakteristik Perairan Muara Sungai Banyuasin}

Sungai Banyuasin yang terletak di bagian pesisir Pantai Timur Sumatera Selatan merupakan lahan pasang surut sehingga harus dikelola dengan baik. Perairan muara Sungai Banyuasin merupakan daerah perairan tempat bermuaranya berbagai sungai. Beberapa muara sungai yang terdapat di Pantai Timur Kabupaten Banyuasin bermuara di Selat Bangka dan kini telah menjadi daerah lalu lintas transportasi air atau daerah alur lintasan kapal, baik kapal yang digunakan penduduk maupun kapal-kapal nelayan [6].

Daerah muara Sungai Banyuasin ini merupakan daerah yang sangat dipengaruhi oleh pasang surut. Pergerakan arus laut di perairan muara Sungai Banyuasin ini dipengaruhi oleh fenomena pasang surut. Pergerakan arus laut pada perairan muara Sungai Banyuasin ini akan bergerak bolak-balik seiring dengan naik turunnya muka air laut akibat adanya pasang surut. Pasang surut akan meyebabkan gerakan horizontal yang periodik serta menimbulkan debit aliran massa air yang besar atau disebut juga dengan arus pasang surut [7].

\section{F. Gaya Gesek Pada Sebuah Ban}

Gaya gesek adalah gaya yang arahnya berlawanan dengan arah gerak benda. Gaya gesek muncul ketika dua buah benda saling bersentuhan. Besar kecilnya gaya gesek ditentukan oleh gaya normal yang bekerja dan koefisien gesek antara kedua benda yang bersentuhan. Nilai dari koefisien gesek bervariasi.

Besar kecilnya nilai koefisien dipengaruhi oleh bentuk permukaan yang bersentuhan antara dua benda, yaitu alur dari ban dan permukaan jalan. Koefisien gesek statis antara ban dengan jalan yang kering adalah sekitar 0.7 , sementara koefisien gesek statis antara ban dengan jalan yang basah adalah sekitar 0.4 [8]. Namun, nilai koefisien tidak dapat ditentukan secara pasti. Hal ini dikarenakan juga ada faktor lain yaitu kondisi ban dan komposisi bahan jalan. Faktor tersebut dapat menurunkan koefisien gesek statis antara ban dengan jalan yang basah hingga serendah 0.1 [9].

\section{METODOLOGI}

\section{A. Identifikasi Masalah}

Identifikasi dilakukan guna mengetahui masalah apa saja yang dapat timbul dari obyek yang dalam hal ini adalah KMP. Kayong Utara. Selanjutnya adalah merumuskan masalah dari masalah yang telah didapatkan. Fungsi dari perumusan masalah tidak lain agar penyelesaian dari masalah yang dibahas jelas.

\section{B. Studi Literatur}

Studi literatur yang dilakukan yaitu pembelajaran dan pengumpulan referensi teori-teori yang berkaitan dengan analisis serta hal-hal yang berkaitan dengan kecelakaan KMP. Kayong Utara. Langkah-langkah yang dilakukan dalam tahap studi literatur adalah sebagai berikut:

1) Mempelajari teori stabilitas dan teori terbaliknya sebuah kapal.

2) Mempelajari kecelakaan transportasi laut dan karakteristiknya.

3) Mempelajari investigasi kecelakaan transportasi.

4) Mempelajari karakteristik perairan muara Sungai Banyuasin.
5) Mempelajari koefisien gaya gesek statis pada permukaan ban pada kondisi basah.

\section{Pengumpulan Data}

Data yang dikumpulkan adalah data yang berkaitan dengan kecelakaan KMP. Kayong Utara. Data yang dikumpulkan adalah data sekunder yang relevan dan mendukung serta mencakup segala aspek yang berhubungan dengan penelitian yang akan dilakukan yang meliputi hasil temuan lapangan, stability booklet, lines plan, dan general arrangement.

\section{Pemodelan}

Permodelan kapal dibuat berdasarkan data gambar lines plan, general arrangement, dan stability booklet yang telah didapat. Proses permodelan dibantu dengan menggunakan software Maxsurf Modeler. Skala yang digunakan dalam pembuatan model adalah 1:1 sehingga ukuran model sama dengan ukuran kapal yang sebenarnya. Permodelan juga mencakup model lambung kapal, bangunan atas, internal structure serta model tangki-tangki yang disesuaikan dengan data stability booklet kapal. Dalam proses analisis, model yang digunakan adalah model yang disederhanakan yaitu berupa lambung kapal saja dengan tujuan untuk dapat meringankan kinerja dari perangkat lunak Maxsurf Stability. Model kapal yang lengkap digunakan sebagai bahan visualisasi dari hasil analisis yang didapat, sehingga kondisi kapal hasil analisis dapat tergambarkan atau terbayang dengan mudah.

\section{E. Pemeriksaan dan Koreksi Model}

Pemeriksaan dan koreksi model dilakukan dengan toleransi selisih tidak lebih dari $0.2 \%$. Sehingga model kapal yang dibuat mendekati sesuai dengan kapal yang sebenarnya. Pemeriksaan dan koreksi model dilakukan pada model lambung, kapasitas tangki, dan titik berat tangki yang sesuai dengan data kapasitas tangki pada stability booklet.

\section{F. Perencanaan Kondisi Pembebanan (Load Case)}

Perencanaan kondisi pembebanan pada model disesuaikan dengan kondisi pembebanan pada kapal saat terjadinya kecelakaan. Kondisi tersebut ditinjau dari hasil temuan lapangan yang telah dilakukan oleh KNKT.

\section{G. Simulasi Kecelakaan dan Analisis Stabilitas}

Simulasi kecelakaan dilakukan pada model kapal. Tangkitangki yang kosong maupun terisi disesuaikan dengan sebagaimana yang dilaporkan pada hasil temuan lapangan. Simulasi kecelakaan dilakukan secara bertahap sesuai dengan hasil temuan lapangan. Data dan hasil yang didapat dari simulasi stabilitas dianalisis untuk mengetahui penyebab kecelakaan.

\section{H. Pembahasan}

Dilakukan pembahasan tentang penyebab terjadinya kecelakaan, hal apa saja yang dapat menghindari terjadinya kecelakaan kapal, serta rekomendasi yang dianjurkan agar kecelakaan serupa tidak terjadi kembali.

\section{Kesimpulan dan Saran}

Dilakukan penarikan kesimpulan berupa kondisi kapal pada saat kecelakaan, penyebab kecelakaan, hal-hal yang dapat dilakukan untuk menghindari kecelakaan, dan rekomendasi 
untuk meningkatkan keselamatan pelayaran. Hal ini dilakukan agar kecelakaan serupa tidak terjadi kembali.

\section{ANALISIS DAN PEMBAHASAN}

\section{A. Loadcase}

Berdasarkan hasil temuan lapangan kecelakaan KMP. Kayong utara yang dilakukan oleh KNKT, resume kronologi kecelakaan dapat dilihat pada Gambar 2.

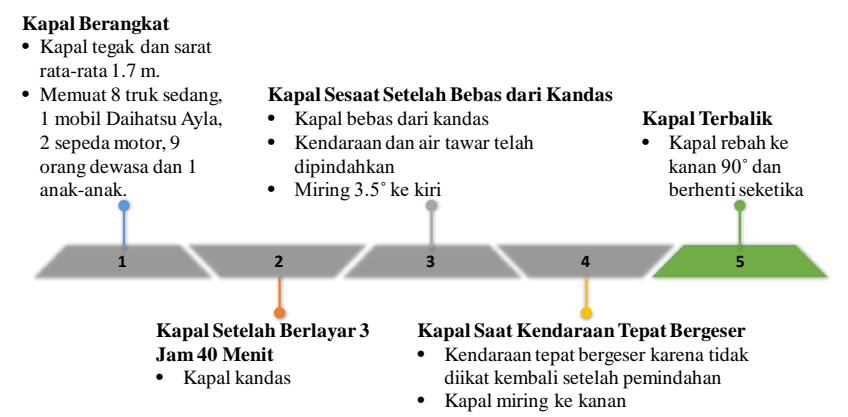

Gambar 2. Kronologi kecelakaan KMP. Kayong Utara.

Analisis dilakukan pada beberapa kejadian sehingga didapatkan kondisi pembebanan berdasarkan kronologi kecelakaan untuk memudahkan proses analisis stabilitasnya. Tahap analisis tersebut terdiri dari 5 kejadiaan kapal dan 2 kemungkinan kejadian yang mendukung terbalik kapal. Adapun kondisi-kondisi pembebanan (loadcase) yang dianalisis dapat dilihat pada Tabel 2.

\section{B. Pemodelan}

Pemodelan yang dilakukan meliputi permodelan lambung, permodelan tangki, dan juga permodelan rencana umum kapal yang dibuat berdasarkan data gambar lines plan, general arrangement, dan capacity plan yang telah didapat dengan skala 1:1. Model kapal dapat dilihat pada Gambar 3.

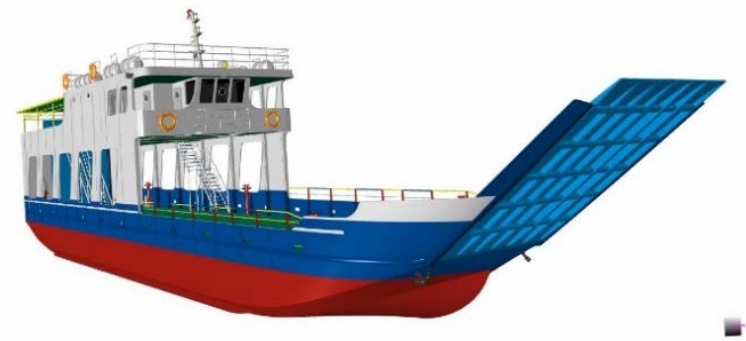

Gambar 3. Model KMP. Kayong Utara.

Selanjutnya dilakukan pemeriksaan, koreksi, serta validasi model pada model lambung kapal dan tangki dengan toleransi selisih $0.2 \%$. Hasil pemeriksaan, koreksi, serta validasi model dapat dilihat pada Tabel 3.

\section{Analisis Stabilitas Kapal Berangkat}

Temuan yang didapatkan pada saat kondisi kapal berangkat adalah sebagai berikut:

1) Displacement bernilai 356.4 ton.

2) $\mathrm{LCB}=\mathrm{LCG}=14.245 \mathrm{~m}$ dari AP.

3) Isi tangki disesuaikan dapat dilihat pada Gambar 4.

4) Massa lightship disesuaikan menjadi 130.7 ton dan LCG lightship menjadi $19.3 \mathrm{~m}$ dari AP.

5) Perkiraan peletakkan muatan kendaraan dapat dilihat pada Gambar 4.
Berdasarkan kondisi tersebut kemudian dianalisis sehingga didapatkan kurva stabilitas lengan GZ serta kondisi equilibrium kapal yang dapat dilihat pada Gambar 5.

Tabel 2.

Kondisi pembebanan kapal

\begin{tabular}{|c|c|}
\hline Kejadian & Kondisi \\
\hline Kapal Berangkat & $\begin{array}{l}\text { Bahan bakar dan air tawar penuh, kapal } \\
\text { tegak dengan sarat } 1.7 \mathrm{~m} \text {. }\end{array}$ \\
\hline $\begin{array}{l}\text { Kapal Setelah Berlayar } 3 \\
\text { Jam } 40 \text { Menit }\end{array}$ & $\begin{array}{l}\text { Kapal tepat sebelum kandas, bahan bakar } \\
94.55 \% \text {, air tawar } 83.99 \% \text {. }\end{array}$ \\
\hline $\begin{array}{l}\text { Kapal Sesaat Setelah Bebas } \\
\text { dari kandas }\end{array}$ & $\begin{array}{l}\text { Kapal terapung, bahan bakar } 94.55 \% \text {, } \\
\text { tangki air tawar kiri } 71.6 \% \text {, tangki air tawar } \\
\text { kanan } 96.38 \% \text {, kendaraan dipindahkan, } \\
\text { momen penegak belum bekerja }\end{array}$ \\
\hline $\begin{array}{l}\text { Kapal Saat Kendaraan } \\
\text { Tepat Akan Bergeser }\end{array}$ & $\begin{array}{l}\text { Kapal terapung, bahan bakar } 94.55 \% \text {, } \\
\text { tangki air tawar kiri } 71.6 \% \text {, tangki air tawar } \\
\text { kanan } 96.38 \% \text {, kendaraan tepat akan } \\
\text { bergeser, momen penegak telah bekerja }\end{array}$ \\
\hline $\begin{array}{l}\text { Kapal Setelah Kendaraan } \\
\text { Bergeser }\end{array}$ & $\begin{array}{l}\text { Kapal belum terbalik, bahan bakar } 94.55 \% \text {, } \\
\text { tangki air tawar kiri } 71.6 \% \text {, tangki air tawar } \\
\text { kanan } 96.38 \% \text {, kendaraan telah bergeser, } \\
\text { momen penegak telah bekerja }\end{array}$ \\
\hline $\begin{array}{l}\text { Kapal } \\
\text { Kemungkinan } 1\end{array}$ & $\begin{array}{l}\text { Kapal terbalik, bahan bakar } 94.55 \% \text {, tangki } \\
\text { air tawar kiri } 62 \% \text {, tangki air tawar kanan } \\
96.38 \% \text {, kendaraan telah bergeser, momen } \\
\text { penegak telah bekerja }\end{array}$ \\
\hline $\begin{array}{l}\text { Kapal } \\
\text { Kemungkinan } 2\end{array}$ & $\begin{array}{l}\text { Kapal terbalik, bahan bakar } 94.55 \% \text {, tangki } \\
\text { air tawar kiri } 71.6 \% \text {, tangki air tawar kanan } \\
96.38 \% \text {, kendaraan telah bergeser, momen } \\
\text { penegak telah bekerja, VCG lightship } 1.8 \mathrm{~m}\end{array}$ \\
\hline
\end{tabular}

Tabel 3.

Kondisi pembebanan kapal

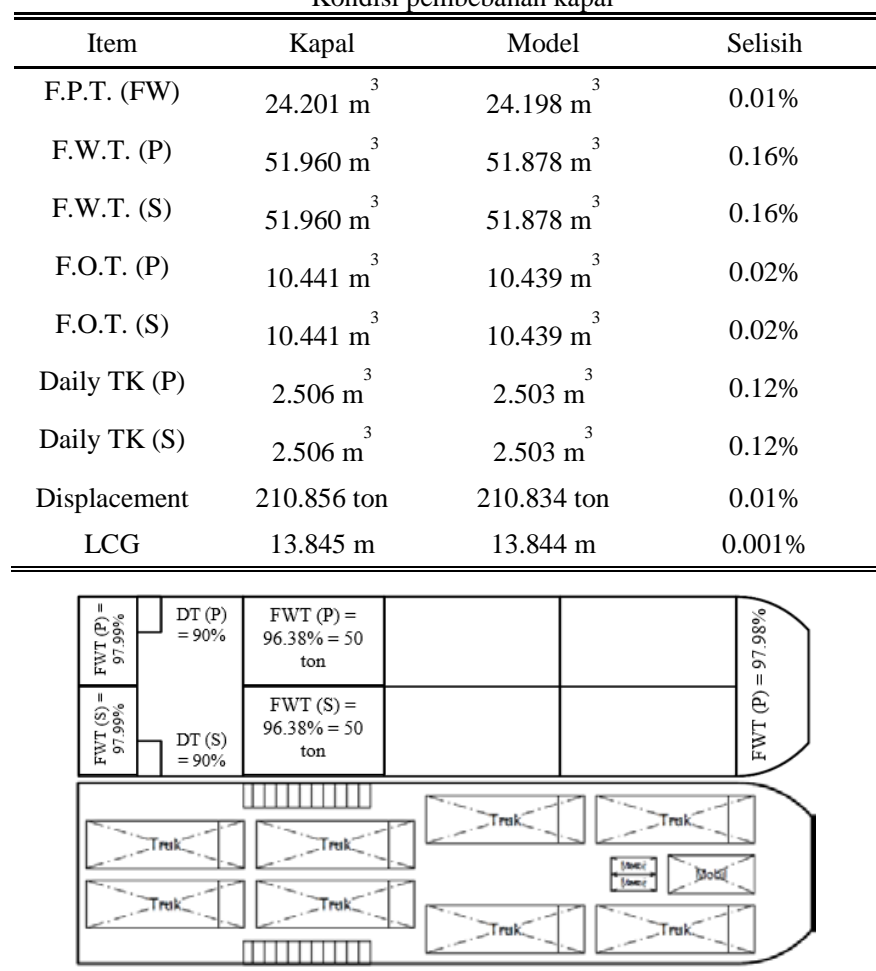

Gambar 4. Perkiraan kondisi tangki dan posisi kendaraan kapal berangkat

Diketahui bahwa kurva stabilitas lengan GZ yang bernilai positif dan hasil pemeriksaan kriteria stabilitas menurut IMO Resolution A.749(18) serta trim 1\% Lpp adalah tidak memenuhi 
yang dapat dilihat pada Tabel 4. Ilustrasi kondisi kapal berangkat dapat dilihat pada Gambar 6 .

Kurva Stabilitas Lengan GZ Kapal Berangkat

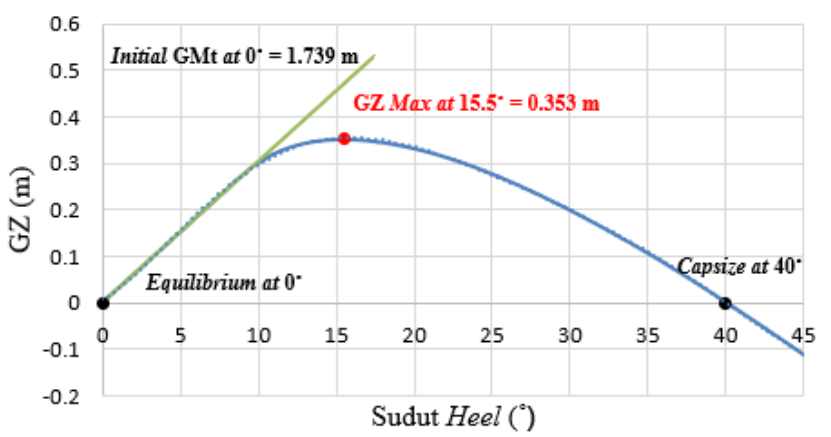

Gambar 5. Kurva stabilitas lengan GZ kapal berangkat

Tabel 4.

Pemeriksaan kriteria stabilitas dan trim kapal berangkat

\begin{tabular}{lcc}
\hline \multicolumn{1}{c}{ Criteria } & Result & Status \\
\hline Area $0^{\circ}$ to $30^{\circ}(3.151 \mathrm{~m} . \mathrm{deg})$ & 7.6788 & Pass \\
Area $0^{\circ}$ to $40^{\circ}(5.157 \mathrm{~m} . \mathrm{deg})$ & 8.7222 & Pass \\
Area $30^{\circ}$ to $40^{\circ}(1.719 \mathrm{~m} . \mathrm{deg})$ & 1.0433 & Fail \\
Max GZ at $30^{\circ}$ or Greater $(0.2 \mathrm{~m})$ & 0.200 & Pass \\
Angle of Maximum GZ $\left(\theta \mathrm{Max} \geq 25^{\circ}\right)$ & 15.5 & Fail \\
Initial GMt $(0.15 \mathrm{~m})$ & 1.739 & Pass \\
Passenger Crowding: Angle of Equilibrium $\left(\leq 10^{\circ}\right)$ & 0.3 & Pass \\
Trim $( \pm 1 \%$ LPP $= \pm 0.292 \mathrm{~m})$ & 0 & Pass \\
\hline \hline
\end{tabular}

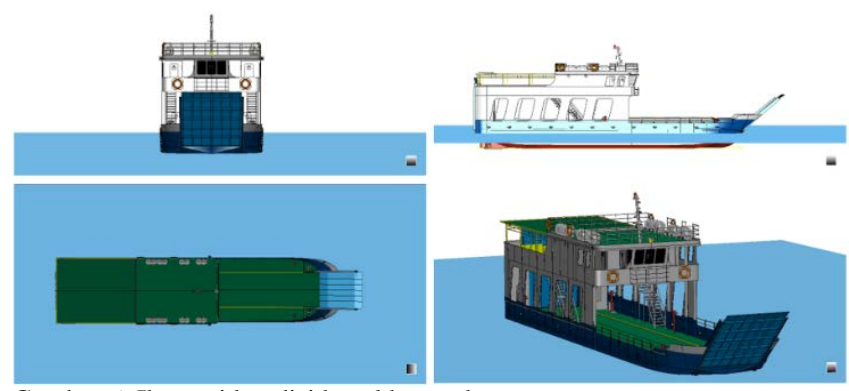

Gambar 6. Ilustrasi kondisi kapal berangkat

\section{Analisis Stabilitas Kapal Setelah Berlayar 3 Jam 40 Menit}

Temuan-temuan yang didapatkan pada kondisi kapal setelah berlayar 3 jam 40 menit adalah sebagai berikut:

1) Konsumsi bahan bakar selama 3 jam 40 menit beroperasi adalah 0.6025 ton.

2) Berat air tawar sebelum pemindahan untuk setiap tangki adalah 43.572 ton sehingga kondisi tiap-tiap tangki dapat dilihat pada Gambar 7.

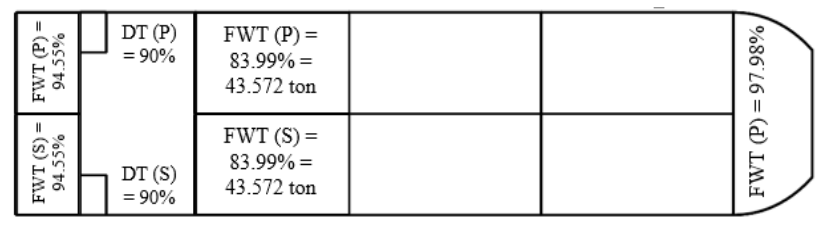

Gambar 7. Perkiraan kondisi tangki kapal setelah berlayar 3 jam 40 menit

Didapatkan kurva stabilitas lengan GZ yang dapat dilihat pada Gambar 8 bernilai positif serta hasil pemeriksaan stabilitas dan trim dibawah $\pm 1 \%$ LPp yang tidak memenuhi yang dapat dilihat pada Tabel 5. Ilustrasi kondisi pada saat kapal kandas dapat dilihat pada Gambar 9.

\section{Kurva Stabilitas Lengan GZ Kapal Setelah Berlayar 3 Jam 40 Menit}

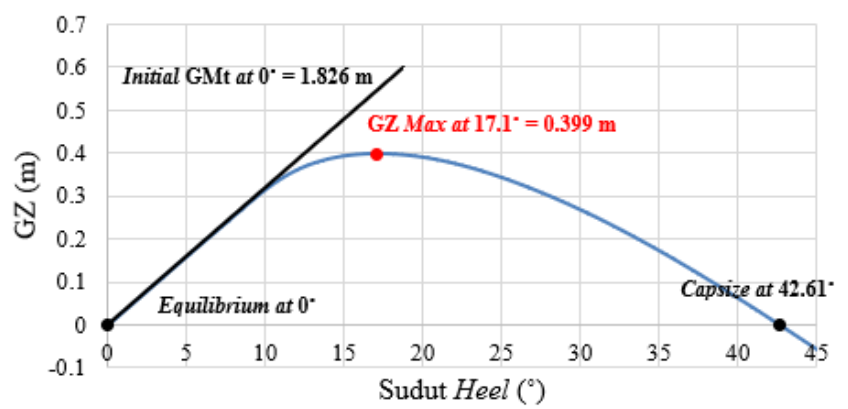

Gambar 8. Kurva stabilitas lengan GZ kapal setelah berlayar 3 jam 40 menit

Tabel 5.

Pemeriksaan kriteria stabilitas dan trim kapal setelah berlayar 3 jam 40 menit

\begin{tabular}{lcc}
\hline \multicolumn{1}{c}{ Criteria } & Result & Status \\
\hline Area $0^{\circ}$ to $30^{\circ}(3.151 \mathrm{~m} . \mathrm{deg})$ & 8.7830 & Pass \\
Area $0^{\circ}$ to $40^{\circ}(5.157 \mathrm{~m} . \mathrm{deg})$ & 10.483 & Pass \\
Area $30^{\circ}$ to $40^{\circ}(1.719 \mathrm{~m} . \mathrm{deg})$ & 1.7002 & Fail \\
Max GZ at $30^{\circ}$ or Greater $(0.2 \mathrm{~m})$ & 0.268 & Pass \\
Angle of Maximum GZ $\left(\theta \mathrm{Max} \geq 25^{\circ}\right)$ & 17.1 & Fail \\
Initial GMt $(0.15 \mathrm{~m})$ & 1.826 & Pass \\
Passenger Crowding: Angle of Equilibrium $\left(\leq 10^{\circ}\right)$ & 0.3 & Pass \\
Trim $( \pm 1 \%$ LPP $= \pm 0.292 \mathrm{~m})$ & -0.172 & Pass \\
\hline \hline
\end{tabular}

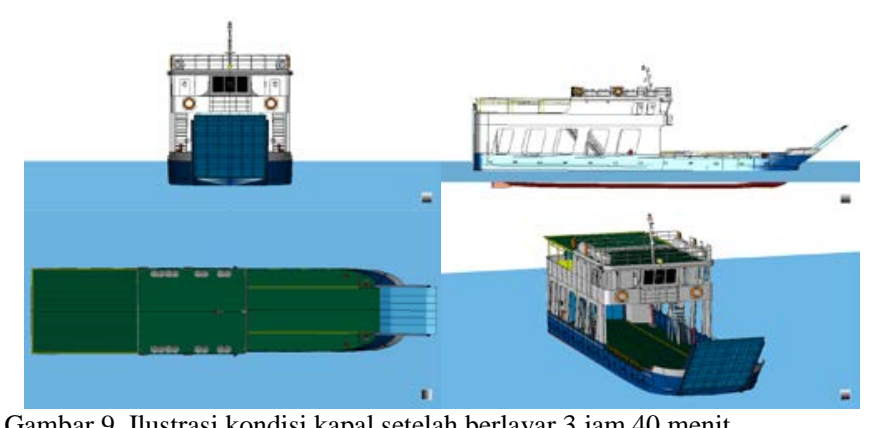

Gambar 9. Ilustrasi kondisi kapal setelah berlayar 3 jam 40 menit

\section{E. Analisis Stabilitas Kapal Sesaat Setelah Bebas dari Kandas}

Pada saat kandas, dilakukan upaya pemindahan kendaraan untuk dapat membebaskan kapal dari kandas dengan kondisi miring $4^{\circ}$ ke kiri dan sedikit trim buritan. Sehingga, temuantemuan yang didapatkan pada kondisi kapal sesaat setelah bebas dari kandas adalah sebagai berikut:

1) Perkiraan posisi kendaraan akhir setelah dilakukan pemindahan pada 4 truk paling belakang dapat dilihat pada Gambar 10.

2) Isi tangki air tawar setelah dilakukan pemindahan serta tangki lainnya dapat dilihat pada Gambar 10.

3) Kapal terapung dan miring $3.5^{\circ}$ dan sedang tidak pada equilibrium.

4) Akan bekerja momen penegak bernilai 38.29 ton.m.

Perkiraan kendaraan 4 truk paling belakang disesuaikan dengan hasil temuan lapangan. Hal ini didasari oleh posisi kendaraan sebelum pemindahan dan ruang tersisa yang memungkinkan untuk diletakkannya truk di posisi yang baru. Truk tidak diikat kembali setelah dipindahkan. Sehingga kombinasi dari bekerjanya momen penegak kapal, kemungkinan bergeser truk akibat tidak diikat kembali setelah 
dipindahkan, serta tidak seimbangnya tangki air tawar sanggup untuk merebahkan kapal ke kanan.

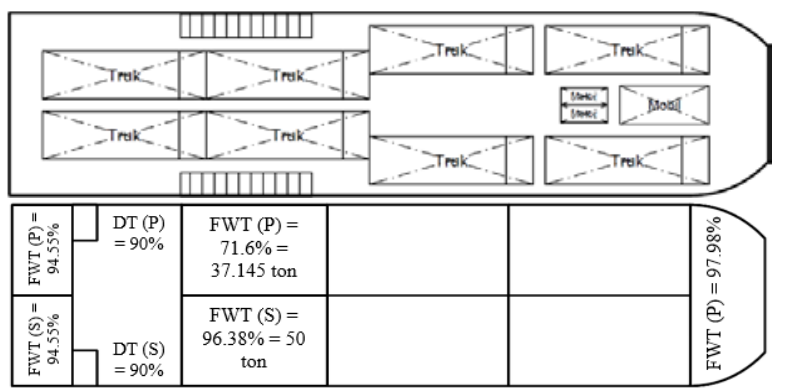

Gambar 10. Perkiraan posisi kendaraan kapal (atas) dan kondisi tangki (bawah) sesaat setelah bebas dari kandas

Didapatkan kurva stabilitas lengan GZ yang bernilai positif yang dapat dilihat pada Gambar 11 serta hasil pemeriksaan stabilitas dan trim dibawah $\pm 1 \%$ Lpp yang tidak memenuhi dapat dilihat pada Tabel 6. Ilustrasi kondisi kapal sesaat setelah bebas dari kandas dapat dilihat pada Gambar 12.

Kurva Stabilitas Lengan GZ Kapal Sesaat Setelah Bebas dari Kandas

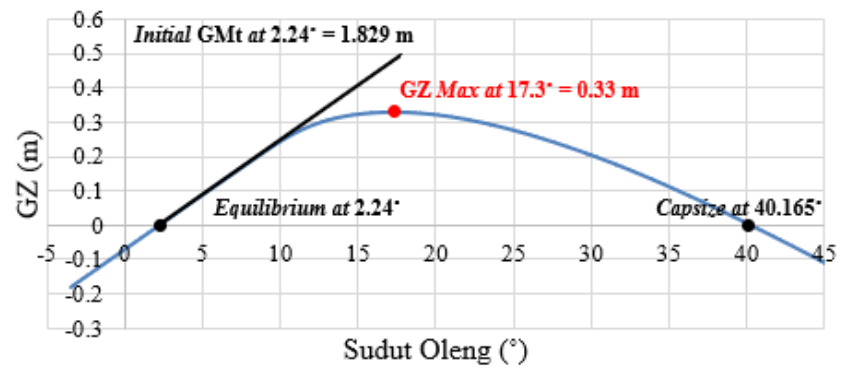

Gambar 11. Kurva stabilitas lengan GZ kapal sesaat setelah bebas dari kandas

Tabel 6.

Pemeriksaan kriteria stabilitas dan trim kapal sesaat setelah bebas dari kandas

\begin{tabular}{lcc}
\hline \hline \multicolumn{1}{c}{ Criteria } & Result & Status \\
\hline Area $0^{\circ}$ to $30^{\circ}(3.151 \mathrm{~m} . \mathrm{deg})$ & 6.7024 & Pass \\
Area $0^{\circ}$ to $40^{\circ}(5.157 \mathrm{~m} . \mathrm{deg})$ & 7.7898 & Pass \\
Area $30^{\circ}$ to $40^{\circ}(1.719 \mathrm{~m} . \mathrm{deg})$ & 1.0875 & Fail \\
Max GZ at $30^{\circ}$ or Greater $(0.2 \mathrm{~m})$ & 0.203 & Pass \\
Angle of Maximum GZ $\left(\theta \mathrm{Max} \geq 25^{\circ}\right)$ & 17.3 & Fail \\
Initial GMt $(0.15 \mathrm{~m})$ & 1.829 & Pass \\
Passenger Crowding: Angle of Equilibrium $\left(\leq 10^{\circ}\right)$ & 2.6 & Pass \\
Trim $( \pm 1 \%$ LPP $= \pm 0.292 \mathrm{~m})$ & -0.171 & Pass \\
\hline \hline
\end{tabular}

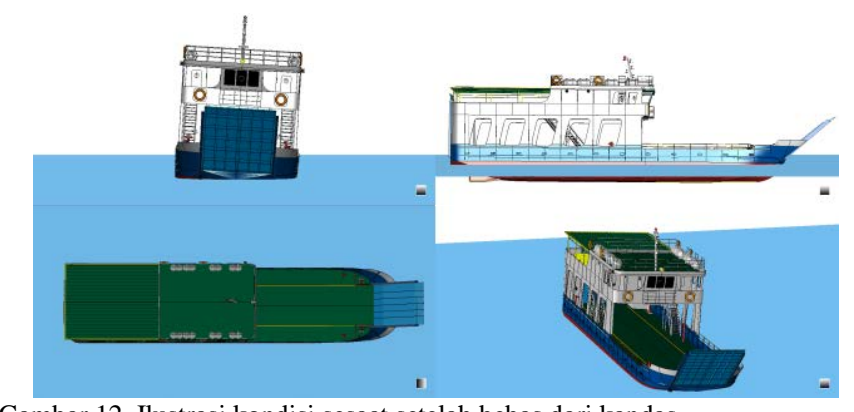

Gambar 12. Ilustrasi kondisi sesaat setelah bebas dari kandas

\section{F. Analisis Stabilitas Kapal Saat Kendaraan Tepat Akan Bergeser}

Akibat tidak seimbangnya kedua tangki air tawar dan bekerjanya momen penegak kapal yang memutar kapal ke kanan, kapal akan terus miring ke kanan pada saat kapal terapung kembali setelah bebas dari kandas. Kapal terus miring ke kanan sehingga kendaraan truk bergeser akibat tidak diikat kembali dan kondisi pengikatan yang kurang baik. Bergesernya kendaraan berkaitan langsung dengan koefisien gesek statis ban kendaraan. Pada saat kejadian, disebutkan bahwa telah terjadi hujan gerimis sehingga kondisi dari koefisien gesek statis ban kendaraan adalah pada kondisi basah yang bernilai 0.1[3]. Kemiringan kapal pada saat kendaraan tepat bergeser adalah

$$
\begin{aligned}
\theta & =\tan ^{-1}(0.1) \\
& =5,7106^{\circ}
\end{aligned}
$$

Sehingga pada kemiringan $5.7106^{\circ}$ titik berat kapal telah bergeser ke kanan akibat dari bergesernya kendaraan. Sehingga temuan-temuan yang didapatkan pada kondisi kapal sesaat setelah bebas dari kandas adalah sebagai berikut:

1) Sudut kemiringan kapal saat kendaraan tepat bergeser adalah $5.71^{\circ}$ merupakan kombinasi dari tidak seimbangnya tangki air tawar dan momen penegak.

2) Telah bekerja momen penegak kapal yang besarnya adalah 38.29 ton.m.

3) Miring akibat selisih berat air $=2.24^{\circ}$

Didapatkan kurva stabilitas lengan GZ yang bernilai positif yang dapat dilihat pada Gambar 13 serta hasil pemeriksaan stabilitas dan trim dibawah $\pm 1 \%$ LPP yang tidak memenuhi yang dapat dilihat pada Tabel 7. Equilibrium terjadi pada sudut oleng $5.723^{\circ}$ sementara kendaraan akan mulai bergeser pada sudut $5.7106^{\circ}$. Ilustrasi kondisi kapal saat kendaraan tepat akan bergeser dapat dilihat pada Gambar 14.

\section{Kurva Stabilitas Lengan GZ Kapal Saat Kendaraan Tepat Akan Bergeser}

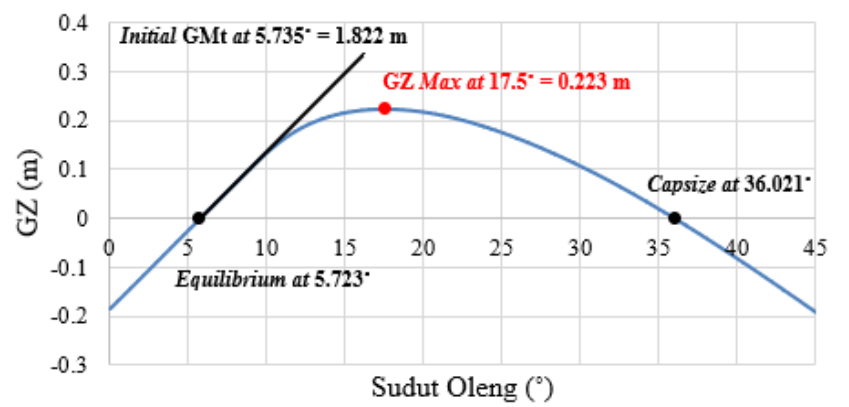

Gambar 13. Kurva stabilitas lengan GZ kapal saat kendaraan tepat akan bergeser

Tabel 7.

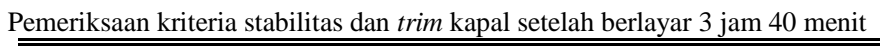

\begin{tabular}{lll}
\hline \multicolumn{1}{c}{ Criteria } & Result & Status \\
\hline Area $0^{\circ}$ to $30^{\circ}(3.151 \mathrm{~m} . \mathrm{deg})$ & 3.5042 & Pass \\
Area $0^{\circ}$ to $40^{\circ}(5.157 \mathrm{~m} . \mathrm{deg})$ & 3.8381 & Fail \\
Area $30^{\circ}$ to $40^{\circ}(1.719 \mathrm{~m} . \mathrm{deg})$ & 0.3339 & Fail \\
Max GZ at $30^{\circ}$ or Greater $(0.2 \mathrm{~m})$ & 0.107 & Fail \\
Angle of Maximum GZ $\left(\theta \mathrm{Max} \geq 25^{\circ}\right)$ & 17.5 & Fail \\
Initial GMt $(0.15 \mathrm{~m})$ & 1.822 & Pass \\
Passenger Crowding: Angle of Equilibrium $\left(\leq 10^{\circ}\right)$ & 6.1 & Pass \\
Trim $( \pm 1 \%$ LpP $= \pm 0.292 \mathrm{~m})$ & -0.172 & Pass \\
\hline \hline
\end{tabular}

\section{G. Analisis Stabilitas Kapal Terbalik}

Temuan yang didapatkan pada kondisi kapal terbalik adalah kemungkinan kapal berada pada kondisi labil dengan kurva 
stabilitas lengan GZ kapal yang selalu bernilai negatif. Sehingga kapal rebah ke kanan $90^{\circ}$ dengan titik berat G melintang yang bergeser ke kanan akibat kendaraan yang bergeser. Ilustrasi bergesernya kendaraan dapat dilihat pada Gambar 15 dan kondisi akhir posisi kendaraan dapat dilihat pada Gambar 16. Hasil analisis ternyata masih didapatkan kurva lengan GZ positif yang dapat dilihat pada Gambar 17.

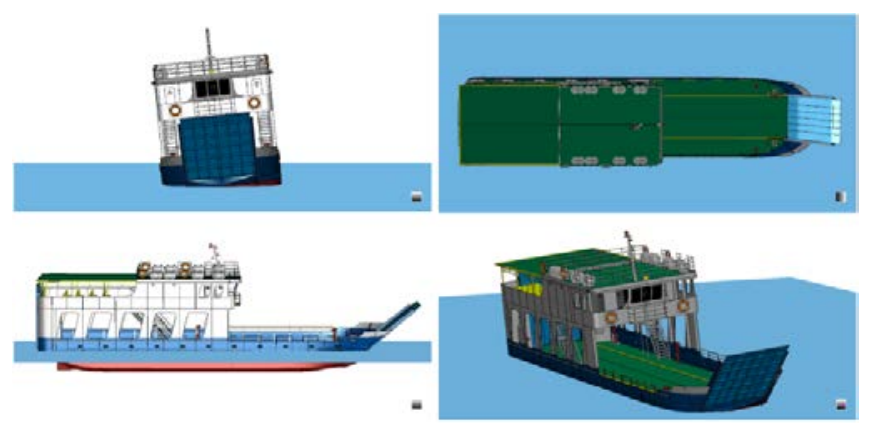

Gambar 14. Ilustrasi kondisi saat kendaraan tepat akan bergeser

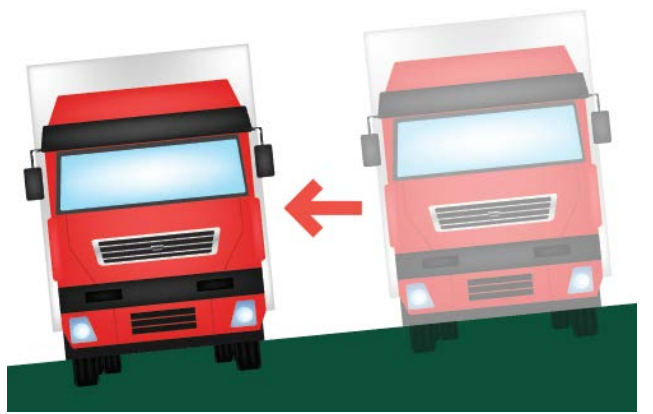

Gambar 15. Ilustrasi bergesernya kendaraan ke kanan

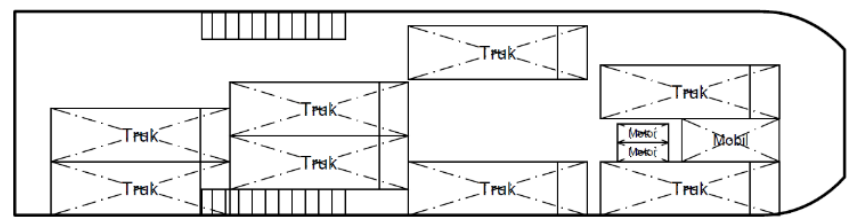

Gambar 16. Perkiraan posisi kendaraan setelah bergeser

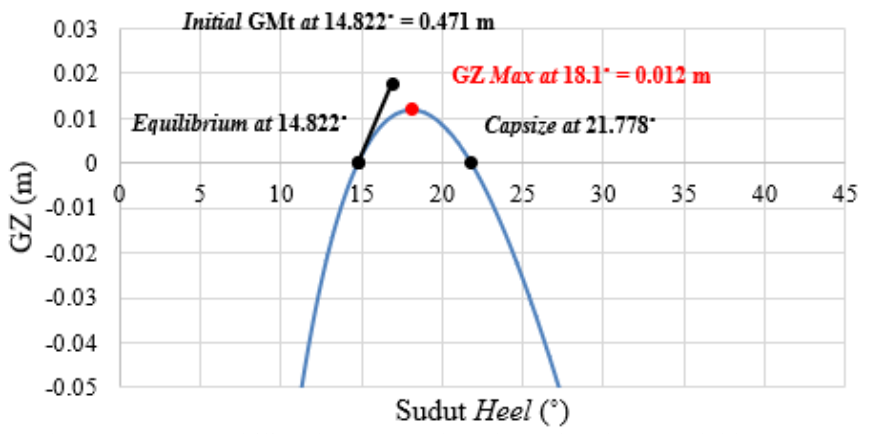

Gambar 17. Kurva stabilitas lengan GZ kapal saat kendaraan telahbergeser

Agar kurva stabilitas lengan GZ selalu bernilai negatif, kemungkinan terjadi salah satu atau keduanya dari kemungkinan berikut:

1) Selisih berat kedua tangki air tawar yang lebih besar.

Kemungkinan pertama adalah isi tangki air tawar kiri yang lebih sedikit dari perkiraan. isi tangki air tawar kiri diubah dari $71.6 \%=37.145$ ton menjadi $62 \%=32.164$ ton. Sehingga kondisi tangki kapal dapat dilihat pada Gambar 18.

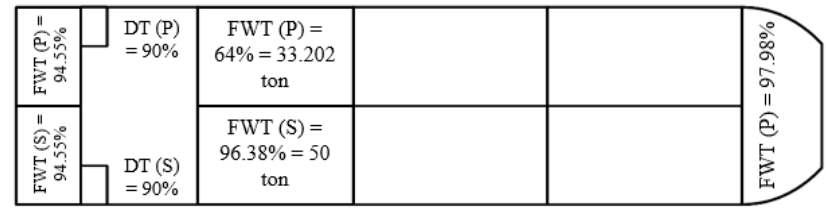

Gambar 18. Perkiraan isi tangki-tangki kapal terbalik kemungkinan I

2) Kenaikan nilai VCG lightship.

Kemungkinan kedua adalah terjadinya kenaikan VCG lightship. Hal ini dilakukan dengan cara VCG lightship dinaikkan dari $1.615 \mathrm{~m}$ menjadi $1.8 \mathrm{~m}$ atau sampai kurva stabilitas lengan GZ selalu bernilai negatif.

Didapatkan kurva stabilitas lengan GZ setelah kendaraan bergeser dan 2 kemungkinan yang mendukung terbaliknya kapal. Kurva stabilias lengan GZ kapal terbalik dapat dilihat pada Gambar 19.

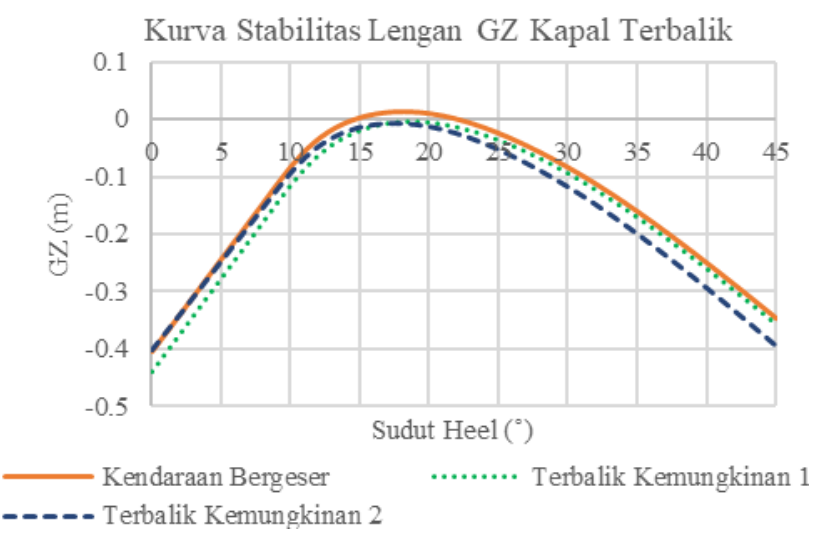

Gambar 19. Kurva Stabilitas Lengan GZ Kapal Terbalik

\section{H. Penyebab Terbaliknya KMP. Kayong Utara}

Berdasarkan hasil analisis, penyebab terbaliknya KMP. Kayong Utara adalah sebagai berikut:

1) Ketidakseimbangan kapal secara melintang yang diakibatkan oleh tidak seimbangnya tangki air tawar kiri dan tangki air tawar kanan akibat tidak dikembalikannya air yang telah dipindahkan ke kondisi semula setelah kapal terapung.

2) Ketidakseimbangan kapal secara melintang akibat dari kendaraan yang bergeser ke sisi kanan karena tidak diikat kembali setelah dilakukan pemindahan.

\section{KESIMPULAN DAN SARAN}

A. Kesimpulan

1) Temuan hasil perhitungan dan analisis pada kecelakaan KMP. Kayong Utara berupa:

a) Pada saat kapal berangkat didapatkan displacement 356.4 ton dan $\mathrm{LCG}=\mathrm{LCB}=14.245 \mathrm{~m}$.

b) Setelah kapal berlayar selama 3 jam 40 menit,

i) Konsumsi bahan bakar adalah 0.6025 ton.

ii) Isi tiap-tiap tangki bahan bakar adalah 94.55\% = 8.291 ton

iii) Isi tiap-tiap tangki air tawar adalah 43.572 ton.

c) Sesaat setelah kapal bebas dari kandas:

i) Kapal terapung serta masih miring $3.5^{\circ}$.

ii) Akan bekerja momen penegak kapal yang besarnya 36.854 ton.m. 
d) Saat kendaraan tepat akan bergeser:

i) Sudut kemiringan tepat bergesernya kendaraan $5.71^{\circ}$.

ii) Miringnya kapal ke kanan merupakan kombinasi dari ketidakseimbangan kedua tangki air tawar dan momen penegak yang bekerja pada kapal.

iii) Telah bekerja momen penegak kapal yang besarnya 36.854 ton.m.

iv) Miring akibat ketidakseimbangan berat air tawar = $2.248^{\circ}$

v) Kondisi equilibrium kapal terjadi pada sudut $5.723^{\circ}$.

e) Pada saat kondisi kapal terbalik kapal berada pada kondisi labil dengan kurva stabilitas lengan GZ kapal yang selalu bernilai negatif.

2) Telah dilakukan pemodelan KMP. Kayong Utara yang berupa permodelan lambung, permodelan tangki, dan permodelan rencana umum yang memenuhi toleransi koreksi $0.2 \%$.

3) Analisis stabilitas kecelakaan KMP. Kayong Utara adalah sebagai berikut:

a) Stabilitas kapal berangkat adalah stabilitas dengan nilai GZ positif, tetapi tidak memenuhi kriteria stabilitas yang disyaratkan.

b) Stabilitas kapal setelah berlayar selama 3 jam 40 menit adalah stabilitas dengan nilai GZ positif, tetapi tidak memenuhi kriteria stabilitas yang disyaratkan.

c) Kondisi kapal sesaat setelah bebas dari kandas adalah belum pada kondisi equilibrium dan akan bekerja momen penegak yang besarnya 38.29 ton.m.

d) Stabilitas kapal pada saat muatan kapal tepat bergeser adalah stabilitas dengan nilai GZ positif, tetapi equilibrium terjadi setelah kendaraan bergeser serta tidak memenuhi kriteria stabilitas yang disyaratkan.

e) Stabilitas kapal terbalik adalah stabilitas dengan nilai GZ yang selalu negatif.
4) Penyebab terbaliknya KMP. Kayong Utara adalah:

a) Ketidakseimbangan kapal secara melintang yang diakibatkan oleh tidak seimbangnya tangki air tawar kiri dan tangki air tawar kanan.

b) Ketidakseimbangan kapal secara melintang akibat bergesernya kendaraan yang bergeser ke sisi kanan.

B. Saran

1) Menyesuaikan prosedur pengikatan kendaraan yang sesuai dengan peraturan dan regulasi yang berlaku agar kendaraan tidak bergeser selama kapal berlayar.

2) Dikembalikannya kendaraan ke posisi asalnya ketika kapal sudah kembali mengapung.

3) Pemindahan air tawar sebaiknya dikembalikan ke tangki asalnya ketika kapal sudah kembali terapung.

4) Melengkapi buku stability booklet kapal yang lebih akurat.

\section{DAFTAR PUSTAKA}

[1] Komite Investigasi Kecelakaan Pelayaran, "Data Investigasi Kecelakaan Pelayaran Th. 2010-2016,” Jakarta, 2016.

[2] Komite Nasional Keselamatan Transportasi (KNKT), "Draft Final KNKT.18.02.06.03 Laporan Investigasi Kecelakaan Pelayaran Kandasnya Kayong Utara,” Jakarta, 2018.

[3] E. . Rawson, K.J. and Tupper, Basic Ship Theory, Vol. 1, 5th ed. Oxford: Butterworth-Heinemann, 2001.

[4] Komite Nasional Keselamatan Transportasi (KNKT), "Laporan Analisis Trend Kecelakaan Laut 2003-2008,”,” Jakarta, 2009.

[5] Komite Investigasi Kecelakaan Pelayaran, "Capaian Kinerja Investigasi Keselamatan Transportasi Tahun 2017,” Jakarta, 2017.

[6] "Letak Geografis Banyuasin,” 2011. [Online]. Available: http://banyuasinkab.go.id/letak-geografis-banyuasin/. [Accessed: 25Dec-2018].

[7] C. M. Simatupang, H. Surbakti, and A. Agussalim, "Analisis data arus di perairan muara sungai Banyuasin, Provinsi Sumatera Selatan,” Maspari J. Mar. Sci. Res., vol. 8, no. 1, pp. 15-24, Feb. 2016.

[8] E. R. Jones and R. L. Childers, Contemporary College Physics, 3rd ed. New York: McGraw Hill, 2001.

[9] R. Nave, "Friction and Automobile Tires," 2017. [Online]. Available: http://hyperphysics.phy-astr.gsu.edu/hbase/Mechanics/frictire.html. [Accessed: 25-Dec-2018]. 